\title{
Tensile and structural properties of natural rubber vulcanizates with different mastication times
}

\author{
Nabil Hayeemasae ${ }^{1,2}$ (D), Siriwat Soontaranon ${ }^{3}$, Mohamad Syahmie Mohamad Rasidi4,5 and \\ Abdulhakim Masa ${ }^{2,6 *}$ (D)

\begin{abstract}
'Department of Rubber Technology and Polymer Science, Faculty of Science and Technology, Prince of Songkla University, Pattani Campus, Pattani, Thailand

${ }^{2}$ Research Unit of Advanced Elastomeric Materials and Innovations for BCG Economy (AEMI), Faculty of Science and Technology,

Prince of Songkla University, Pattani Campus, Pattani, Thailand

${ }^{3}$ Synchrotron Light Research Institute, Muang District, Nakhon Ratchasima, Thailand

${ }^{4}$ Faculty of Chemical Engineering Technology, Universiti Malaysia Perlis (UniMAP), Perlis, Malaysia.

${ }^{5}$ Geopolymer \& Green Technology, Centre of Excellence (CEGeoGTech), Universiti Malaysia Perlis (UniMAP), Perlis, Malaysia

${ }^{6}$ Rubber Engineering and Technology Program, International College, Prince of Songkla University, Hat Yai, Songkhla, Thailand

*abdulhakim.m@psu.ac.th
\end{abstract}

\begin{abstract}
Mastication reduced the molecular weight of natural rubber (NR). This would affect the tensile properties and straininduced crystallization of the rubber vulcanizates due to the structural changes of the rubber molecules. In this study, influences of mastication time on tensile response, deformation-induced crystallization, and structural effects of crosslinked NR were investigated. The crystallization behavior and structural changes during stretching were studied by means of wide angle X-ray scattering (WAXS) and small angle X-ray scattering (SAXS). Increased mastication time significantly affected modulus at specified strain and upturn point of strain-induced crystallization of the crosslinked samples while the tensile strength was influenced slightly by mastication. During stretching, degree of crystallinity at given strain was found to decrease with increasing mastication time, while the crystallite size was reduced. Moreover, the size of crosslinked network structures induced by crosslinking also decreased slightly with increasing mastication time, as suggested by SAXS measurement.
\end{abstract}

Keywords: mastication, natural rubber, strain-induced crystallization, tensile properties.

How to cite: Hayeemasae, N., Soontaranon, S., Rasidi, M. S. M., \& Masa, A. (2021). Tensile and Structural Properties of Natural Rubber Vulcanizates with Different Mastication Times. Polímeros: Ciência e Tecnologia, 31 (1), e2021003. https://doi.org/10.1590/0104-1428.09120

\section{Introduction}

Although natural rubber (NR) has many attractive properties such as high tensile strength and extensibility, good crack growth resistance, and low heat build-up ${ }^{[1]}$, it is never used in its pure form without vulcanization ${ }^{[2]}$. During the compounding, NR requires proper mastication to reduce its molecular weight before incorporating the other chemical ingredients, because excessive molecular weight would prevent dispersion of the added ingredients ${ }^{[3]}$. Since mastication is usually required, the effects of molecular weight reduction through the mastication on tensile properties and on micro-structure are of great interest for understanding the final properties of vulcanizates. Dependence on molecular weight of the properties of rubber was initially investigated by Flory ${ }^{[4]}$ in butyl rubber, and he found that the tensile strength was directly proportional to the weight fraction of the active network structure. Later on, $\mathrm{Kok}^{[5]}$ also reached a similar conclusion for NR. That is, the tensile strength increased with molecular weight. However, in this report, the tensile strength tended to be constant when the molecular weight reached 500,000. Ono et al. ${ }^{[6]}$ investigated the stress-strain properties and strain-induced crystallization of NR vulcanizates with different molecular weights, and reported that a higher molecular weight provided a higher level of stress at a given strain and better strain-induced crystallization ability due to the homogeneous network structures of high molecular weight rubbers. However, no evidence of a network structure was offered. Up to now, the effects of different parameters such as crosslink density, filler content, temperature and deformation rate on the final properties, crystallization behavior and microstructure of NR have been extensively investigated and are well discussed in the report ${ }^{[7]}$, but how the molecular 
weight affects strain-induced crystallization and the network structure is still largely unexplored. Thus, further investigation of the mechanical properties and changes of network structure remains interesting, in order to verify the effects of molecular weight.

It is well accepted that mastication affects NR viscosity due to molecular weight reduction ${ }^{[8,9]}$. Previously, the effect of mastication time on the physical properties and microstructure of uncrosslinked NR was reported ${ }^{[9]}$. Unfortunately, the contributions of mastication time to the network structure and the deformation-induced crystallization behavior of NR after vulcanization were not included. Thus, this work aimed to highlight the effects of molecular weight reduction by mastication on microstructure and final properties of the NR vulcanizates. The NR was initially masticated for various times before addition of the other compounding chemicals. The processing properties of NR were investigated by means of the moving die rheometer. The tensile properties, strain-induced crystallization and network structures of the crosslinked NR were analyzed by means of tensile test, wide angle X-ray diffraction (WAXD) and small angle X-ray scattering (SAXS), respectively.

\section{Materials and Methods}

\subsection{Materials}

Details of rubber and the various chemical ingredients used in the rubber formulation are summarized in Table 1. The quantities of all ingredients are indicated as part(s) per hundred parts of rubber (phr).

\subsection{Sample preparation}

NR was initially masticated for different mastication times $(0,5$ and $10 \mathrm{~min})$ prior to adding the other chemicals. The mastication and compounding were performed in a laboratory-sized internal mixer (Brabender ${ }^{\circledR} \mathrm{GmbH} \& \mathrm{Co}$. KG, Duisburg, Germany) with an initial mixing temperature of $40{ }^{\circ} \mathrm{C}$, a fill factor of 0.8 , and a rotor speed of $60 \mathrm{rpm}$. After the initial mastication, the rubber was further mixed for another $30 \mathrm{sec}$ before incorporating stearic acid and $\mathrm{ZnO}$. When the mixing time reached $1.5 \mathrm{~min}$, an accelerator, CBS, was added and the mixing was continued for another $1 \mathrm{~min}$. Finally, sulfur was incorporated and the compound was further mixed for another $2.5 \mathrm{~min}$. The semi-efficiency system was chosen in this study. The total mixing time after the mastication was kept constant at $5 \mathrm{~min}$ for all compounds. The compounds were left at room temperature for $24 \mathrm{~h}$ prior to the tests. The compounds were pressed in a compression mold at $160^{\circ} \mathrm{C}$ to obtain $1 \mathrm{~mm}$ thick sheets, following their respective curing times $\left(\mathrm{T}_{c 90}\right)$.

\subsection{Characterization}

\subsubsection{Curing characteristics}

A moving die rheometer (Montech MDR 3000 BASIC, Buchen, Germany) was used to assess the curing characteristics of the NR compounds. With the testing temperature set at $160{ }^{\circ} \mathrm{C}$, the curing parameters scorch time $\left(\mathrm{T}_{\mathrm{sl}}\right)$, cure time $\left(\mathrm{T}_{\mathrm{c} 90}\right)$, minimum torque $\left(\mathrm{M}_{\mathrm{L}}\right)$, maximum torque $\left(\mathrm{M}_{\mathrm{H}}\right)$ and torque difference $\left(\mathrm{M}_{\mathrm{H}}-\mathrm{M}_{\mathrm{L}}\right)$ were recorded. Further information on the rheometer can be found elsewhere ${ }^{[10]}$.

The percentage reversion degree was calculated at $300 \mathrm{sec}$ after reaching the maximum curing torque (Maximum torque), in order to estimate the aging resistance of the vulcanizates at an elevated temperature $\left(\mathrm{R}_{300}\right)$. The $\mathrm{R}_{300}$ is defined as follows ${ }^{[1]}$ :

$$
R_{300}=\frac{M_{H}-M_{300}}{M_{H}} \times 100
$$

where $\mathrm{M}_{\mathrm{H}}$ is the maximum torque on the curing curve and $\mathrm{M}_{300}$ is the torque at $300 \mathrm{~s}$ after $\mathrm{M}_{\mathrm{H}}$.

\subsubsection{Equilibrium Swelling}

The equilibrium swelling test was performed in order to estimate the crosslink density $(v)$. The rubber samples were swollen in toluene solvent for $168 \mathrm{~h}$ at room temperature, followed by drying at $70{ }^{\circ} \mathrm{C}$ until constant weight. The $v$ was estimated based on the Flory-Rehner equation ${ }^{[12]}$.

$$
v=-\frac{\ln \left(1-V_{r}\right)+V_{r}+\chi V_{r}^{2}}{2 \rho V_{s}\left(V_{r}^{1 / 3}-\frac{V_{r}}{2}\right)}
$$

where $V_{r}$ is the volume fraction of rubber in the swollen mass, $\chi$ is the polymer-solvent interaction parameter which is equal to 0.39 for the NR-toluene system, $\rho$ is the density of the polymer and $\mathrm{V}_{\mathrm{s}}$ is molar volume of the solvent (106.3 $\mathrm{cm}^{3} / \mathrm{mol}$ ).

\subsubsection{Tensile properties}

The tensile properties of crosslinked NR were investigated by means of a universal tensile testing machine (LLOYD Instruments, LR5K Plus, UK). The test was performed according to ISO37 (type 2). Extensometer was used to measure the strain during tensile testing. Five specimens were used and the results reported are averages.

\subsubsection{Crystallization behavior and structural changes during deformation}

Variations of crystallinity and crystallite size in the vulcanized NR samples during the tensile stretching were investigated by

Table 1. Formulation of the NR compounds.

\begin{tabular}{cc}
\hline Ingredient & Supplier \\
\hline NR (STR 5L) & Chalong Concentrated Natural Rubber Latex Industry Co., Ltd., \\
Songkhla, Thailand & 100 \\
N-cyclohexyl-benzothiazyl-sulphenamide (CBS) & Flexsys America L.P., West Virginia, USA \\
Sulfur & Siam Chemical Co., Ltd., Samut Prakan, Thailand \\
Zinc oxide (ZnO) & Imperial Chemical Co. Ltd., Pathumthani, Thailand \\
Stearic acid & Global Chemical Co. Ltd., Samut Prakarn, Thailand \\
\hline
\end{tabular}


means of WAXD. The structural parameters such as size and dispersion of crosslinked network structures were estimated by means of SAXS measurements. Both WAXD and SAXS were performed at the Siam Photon Laboratory, Synchrotron Light Research Institute (SLRI), Nakhon-Ratchasima, Thailand. The X-ray energy was $9 \mathrm{keV}$ and the measurements were conducted at room temperature $\left(25^{\circ} \mathrm{C}\right)$ with $500 \mathrm{~mm} /$ min extension rate during testing. The tensile machine was in-house developed and a laser system was used to measure the extension between gauges. The exposure time at a fixed strain was 30 seconds and the WAXD and SAXS data were corrected and analyzed by using SAXSIT4.41 software.

From WAXD data, the degree of crystallinity (\%) corresponding to the (200) and (120) planes during stretching were estimated for samples with different mastication times by using the following equation ${ }^{[13]}$.

$$
X_{c}=\frac{A_{c}}{A_{c}+A_{a}} \times 100
$$

where $\mathrm{X}_{\mathrm{c}}$ is the degree of crystallinity, $\mathrm{A}_{\mathrm{c}}$ is the area under crystalline peaks of the (200) or (120) planes, and $A_{a}$ are the area of the amorphous halo.

The average crystallite sizes corresponding to (200) and (120) planes, $\left(\mathrm{L}_{200}\right.$ and $\left.\mathrm{L}_{120}\right)$ were estimated from the Scherrer equation ${ }^{[13,14]}$ :

$$
L_{h k l}=\frac{K \lambda}{\beta \cos \theta}
$$

where, $\mathrm{L}_{\mathrm{hkl}}$ is the average crystallite size in the (200) or (120) planes, $\mathrm{K}$ is equal to $0.89, \lambda$ is the wavelength, $\beta$ is the half-width at half-height, and $\theta$ is the Bragg angle.

Herman's orientation function (OP) was used to estimate the degree of chain orientation during stretching, and it can be defined as follows ${ }^{[15,16]}$ :

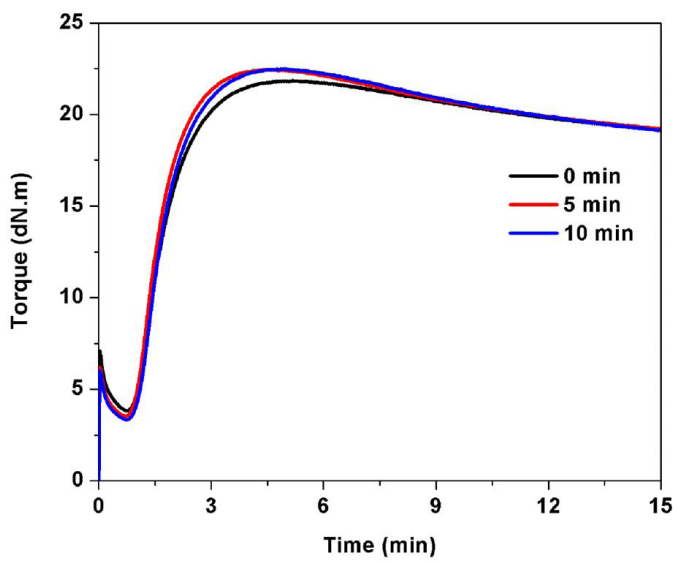

Figure 1. Cure curves of NR vulcanizates prepared with different mastication times.

$$
\begin{aligned}
& O P=\frac{3\left(\cos ^{2} \theta\right)-1}{2} \\
& \left(\cos ^{2} \theta\right)=\frac{\int_{0}^{\pi / 2} I(\phi) \cos ^{2} \phi \sin \phi d \phi}{\int_{0}^{\pi / 2} I(\phi) \sin \phi d \phi}
\end{aligned}
$$

Here $\phi$ is the azimuthal angle and $\mathrm{I}(\phi)$ is the scattered intensity along the angle $\phi$.

Structural changes, e.g., size of crosslinked network structures, with varied mastication times were analyzed by fitting the SAXS profiles with Guinier approximation defined as follows ${ }^{[17,18]}$ :

$$
\begin{aligned}
& I(q)=I_{0} \exp \left(-\frac{q^{2} R_{g}^{2}}{3}\right) \\
& \operatorname{Ln}[I(q)]=\operatorname{Ln}\left[I_{0}\right]-\frac{q^{2} R_{g}^{2}}{3}
\end{aligned}
$$

where $\mathrm{R}_{\mathrm{g}}$ is Guinier's radius, a measure of the size of the scattering object.

\section{Results and Discussions}

\subsection{Curing characteristics}

Torque-time curves during vulcanization of the NR vulcanizates prepared with varied mastication times are shown in Figure 1. Curing characteristics such as $\mathrm{T}_{\mathrm{sl}}, \mathrm{T}_{\mathrm{c} 90}, \mathrm{M}_{\mathrm{L}}, \mathrm{M}_{\mathrm{H}}$, and $\mathrm{M}_{\mathrm{H}}-\mathrm{M}_{\mathrm{L}}$ are listed in Table 2. The $\mathrm{M}_{\mathrm{L}}$, an indication of viscosity and processability of the uncured rubber, decreased with mastication time. The $M_{L}$ is usually proportional to the uncured physical crosslinking or chain entanglement ${ }^{[10]}$ and to molecular weight of rubber. It is well-known that mastication mechanically breaks and shortens long rubber molecular chains ${ }^{[8,9,19]}$. A longer mastication then corresponds to greater molecular weight reduction. In contrast, the $\mathrm{M}_{\mathrm{H}}$ is a measure of the cured compound's stiffness, and it tended to increase with mastication time. Also, the $M_{H}-M_{L}$ torque difference represents the total crosslinking density of the vulcanizate, and it also increased over mastication time. This was simply due to the radicals formed by chain scissions. Shortening the molecular chains may facilitate the reactions of curing precursors with rubber chains during

\begin{tabular}{|c|c|c|c|c|c|c|c|}
\hline Sample & $M_{L}(d N . m)$ & $M_{H}(d N . m)$ & $M_{H}-M_{L}$ (dN.m) & $T_{s 1}(\min )$ & $T_{c 90}(\min )$ & $\mathbf{R}_{300 \mathrm{~s}}$ & $\mathrm{v}\left(\times 10^{-7} \mathrm{~mol} / \mathrm{cm}^{-3}\right)$ \\
\hline $0 \mathrm{~min}$ & $3.81 \pm 0.04$ & $21.73 \pm 0.18$ & $17.92 \pm 0.14$ & $1.01 \pm 0.01$ & $2.94 \pm 0.03$ & $6.62 \pm 0.03$ & $1.10 \pm 0.01$ \\
\hline $5 \mathrm{~min}$ & $3.52 \pm 0.02$ & $22.50 \pm 0.10$ & $18.98 \pm 0.02$ & $0.99 \pm 0.01$ & $2.71 \pm 0.05$ & $7.99 \pm 0.02$ & $1.28 \pm 0.01$ \\
\hline $10 \mathrm{~min}$ & $3.27 \pm 0.10$ & $22.52 \pm 0.04$ & $19.25 \pm 0.14$ & $1.02 \pm 0.02$ & $2.89 \pm 0.02$ & $8.50 \pm 0.07$ & $1.41 \pm 0.01$ \\
\hline
\end{tabular}
vulcanization, due to a reduction of steric hindrances from large molecular chains. Consequently, the crosslink density of the samples increased with mastication time. That the crosslink density increased with mastication time was later

Table 2. Curing characteristics of NR vulcanizates. 
confirmed by using equilibrium swelling test, and the results agreed well with the variation of the $M_{H}-M_{L}$.

Considering $\mathrm{T}_{\mathrm{s} 1}$ and $\mathrm{T}_{\mathrm{c} 90}$, it was found that the $\mathrm{T}_{\mathrm{s} 1}$ appeared to be independent of the mastication time, but the shortest curing time $\left(\mathrm{T}_{\mathrm{c} 90}\right)$ was observed when the rubber was initially masticated for $5 \mathrm{~min}$. Previously, it was demonstrated that non-rubber components in the masticated rubber were more homogeneously distributed throughout the rubber matrix when the rubber was masticated for a comparatively short time (e.g., for less than $5 \mathrm{~min})^{[9]}$. These impurities may be involved in the crosslinking reactions, possibly acting as natural accelerators ${ }^{[20,21]}$. Better chemical crosslinking is expected when the dispersion of these impurities is homogeneous.

The effects of mastication time on aging behavior of the rubber were assessed from the percentage reversion of the vulcanizates at elevated temperatures, by determining $\mathrm{R}_{300}{ }^{[11]}$, and the results are included in Table 2 . A larger $R_{300}$ usually indicates lesser reversion resistance. As the mastication time increased, $\mathrm{R}_{300}$ increased accordingly, suggesting that the ability of rubber molecules to withstand reversion at an elevated temperature diminished. This was clearly due to molecular chain scission. The lower molecular weight rubber was more susceptible to heat degradation ${ }^{[22,23]}$.

\subsection{Tensile properties}

The dependence of stress response during the tensile tests on the mastication time is shown in Figure 2, and the tensile properties in terms of modulus at 100\% (M100), 300\% (M300) and 500\% (M500) strains, tensile strength (TS) and elongation at break (EB) are listed in Table 3. Apparently, the stresses in the vulcanizate sample without mastication (0 min) at all given strains (M100, M300 and M500) were higher than those in rubbers masticated for 5 and $10 \mathrm{~min}$, suggesting that the rubber was stronger without mastication, even though a lower total crosslink density was found for the sample without mastication. The tensile testing results clearly confirm that the effect of molecular weight is more pronounced than that of the total crosslink density. High stress response in the sample without mastication was tentatively attributed to a large proportion of chain entanglements in high molecular weight NR as suggested by the $M_{L}$ value (Table 2). These entanglements are capable of hindering the mobility of rubber chains during deformation, resulting in a higher stress. A reduction of chain entanglements with decreasing rubber molecular weight should be responsible for the decreased tensile stress response ${ }^{[24]}$.

It was also found that the EB tended to increase with mastication time. Since the molecular weight decreased with mastication, a longer mastication time resulted in a lesser molecular weight. For longer mastication, some molecular chains turned to short chains with low molecular weight. Such chains may act as a plasticizer, facilitating extension of the vulcanized sample.

\subsection{Crystallization behavior and structural changes during deformation}

Figure 3 shows combination of WAXD images and real-time stress responses as functions of strain, recorded during the WAXD measurement. It can be seen from Figure 3 that the simultaneous stress response during the WAXD test showed similar trend to the stress response obtained from the tensile test (Figure 2). This indicates that the molecular chains responded similarly during tensile testing and WAXD measurement. This provides scientific proof for the similarity of stress response during WAXD and tensile measurements. It is also noted that the stress response during stretching decreased with mastication time, as this caused molecular chain breakdown and lowered molecular weight of the rubber; hence the tensile properties deteriorated. The appearance in inserted WAXD images

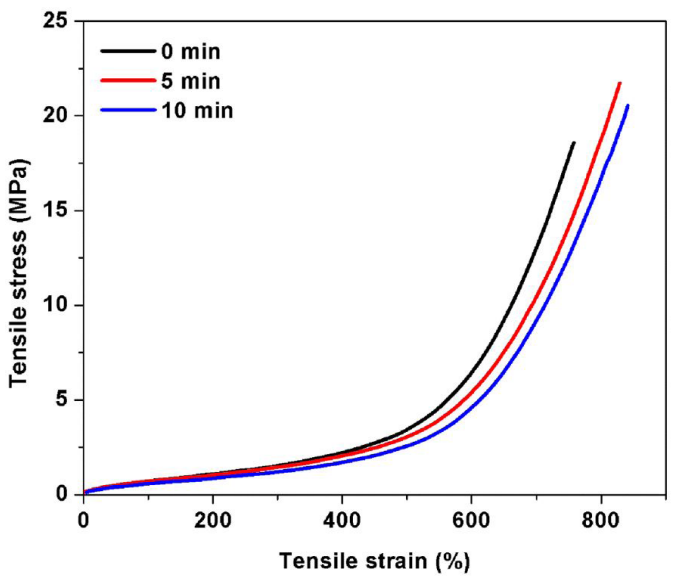

Figure 2. Plot of tensile stress versus tensile strain for NR vulcanizates prepared with different mastication times.

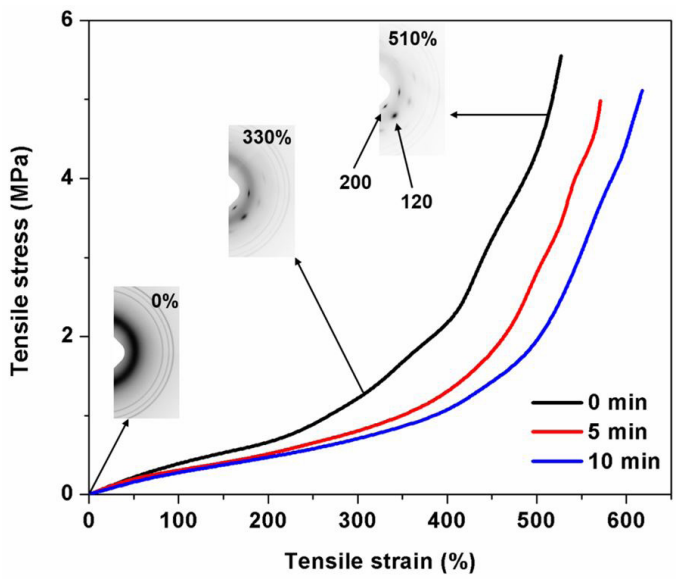

Figure 3. Coupled WAXD images with real time stress responses during WAXD measurement.

Table 3. Tensile properties in terms of M100, M300, M500, TS and EB for NR vulcanizates prepared with different mastication times.

\begin{tabular}{cccccc}
\hline Sample & M100 (MPa) & M300 (MPa) & M500 (MPa) & TS (MPa) & EB (\%) \\
\hline $0 \mathrm{~min}$ & $0.71 \pm 0.04$ & $1.51 \pm 0.03$ & $3.31 \pm 0.01$ & $18.75 \pm 0.21$ & $770 \pm 14$ \\
$5 \mathrm{~min}$ & $0.75 \pm 0.01$ & $1.50 \pm 0.06$ & $3.29 \pm 0.12$ & $21.81 \pm 0.12$ & $812 \pm 19$ \\
$10 \mathrm{~min}$ & $0.71 \pm 0.02$ & $1.44 \pm 0.02$ & $3.04 \pm 0.11$ & $20.48 \pm 0.59$ & $818 \pm 17$ \\
\hline
\end{tabular}


depends strongly on the strain applied. The image without any reflection spot is for the sample without deformation $(0 \%)$, suggesting that no crystallization occurs. When the sample was stretched to $330 \%$ strain, various reflection spots corresponding to different crystallographic planes are seen. However, the (200) and (120) planes are of main interest in this study. These crystallographic planes were more intense with further increase in deformation, implying that the molecular chain orientation and crystallization increased with strain.

Figure 4 shows the variation of crystallinity corresponding to the (200) and (120) planes for the rubber samples prepared with different mastication times. The crystallinity increased with strain in all cases, because stretching caused chain orientation and reduced the degree of disorder of the NR chains $^{[25]}$. These crystallites provided self-reinforcement to the rubber due to their ability to act as virtual filler or as crosslink ${ }^{[7,26]}$. As a result, the tensile stress steeply increased after strain-induced crystallization began. It is also seen that the degree of crystallinity of both crystallographic planes had rank order $0 \mathrm{~min}>5 \mathrm{~min}>10 \mathrm{~min}$. The result clearly suggests that strain-induced crystallization decreased with reduction of molecular weight, achieved via mastication. The decreased crystallinity with increasing mastication time can be explained by increased total crosslink density, as previously shown in Figure 1 and Table 2. Enhanced crosslinking could reduce the mobility or NR chains and delay the orientation of the crystallites during stretching. It is well accepted that the ability for strain-induced crystallization decreases when crosslink density increases, because the molecular chain spans between crosslinks ( $\left.\mathrm{M}_{\mathrm{c}}\right)$ are shortened according to $v=1 / \mathrm{Mc}$, where $v$ is crosslink density. Consequently, the ability to produce large crystallites is lowere $\mathrm{d}^{[27,28]}$. In this case, increased mastication time reduced the molecular chain weight and increased crosslink density of the NR. As a result, the $M_{c}$ was smallish and limited the crystallization during stretching. One may argue that ploting the crystallinity data as a function of stress might be useful. However, the reinforcement of rubber is often defined by an improvement in properties at a given strain, i.e., modulus at a certain strain, and tensile strength. Futhermore, the changes of crystallization during stretching are involved with the rubber deformation particularly at large strains, and reflect the reinforcement of rubber, appearing as a function of stretching level. Thus, plotting the crystallization data as a function of stress might be inappropiate due to the different phenomena in the progression of strain-induced crystallization.

Figure 5 shows variation of the average crystallite size in NR vulcanizates. The size of crystallites appeared to decrease with strain due to the increased number of crystallites with strain (Figure 4), and a reduction of mean distance between the stretched chains which acted as crystallite precursors ${ }^{[29]}$. It is also observed that the average size of crystallite during stretching of the sample without mastication ( $0 \mathrm{~min})$ was slightly smaller than in the samples with 5 and $10 \mathrm{~min}$ of mastication. This is attributed to the large number of crystallites formed in the samples with mastication, resulting in a small average size of crystallite.

To gain a deeper understanding regarding the orientation of crystallites during stretching, Herman's orientation

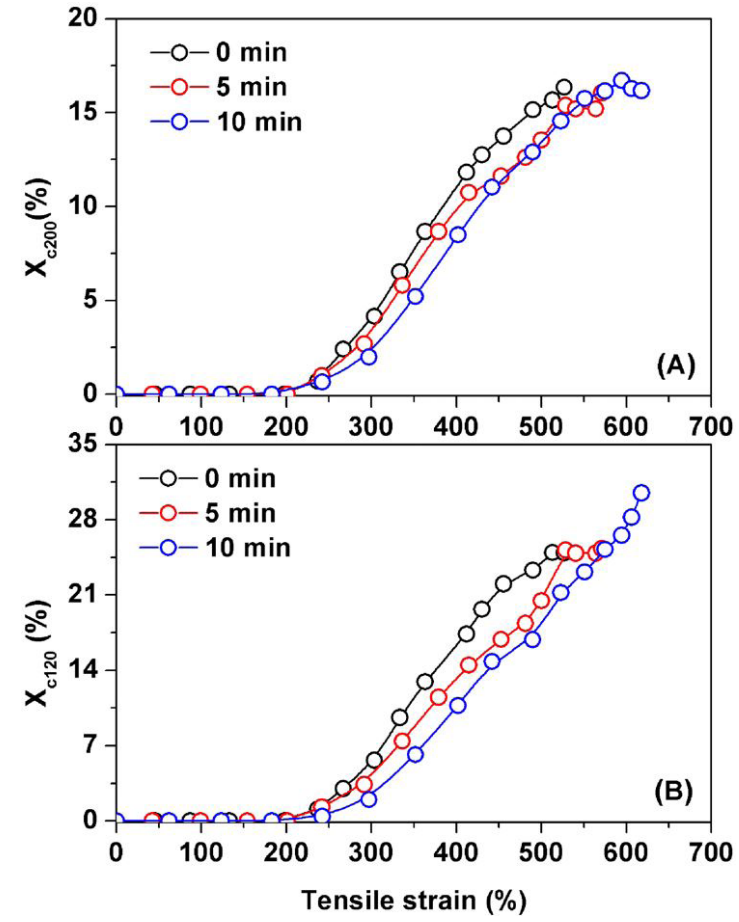

Figure 4. Degree of crystallinity at various strains in the NR vulcanizates prepared with different mastication times.

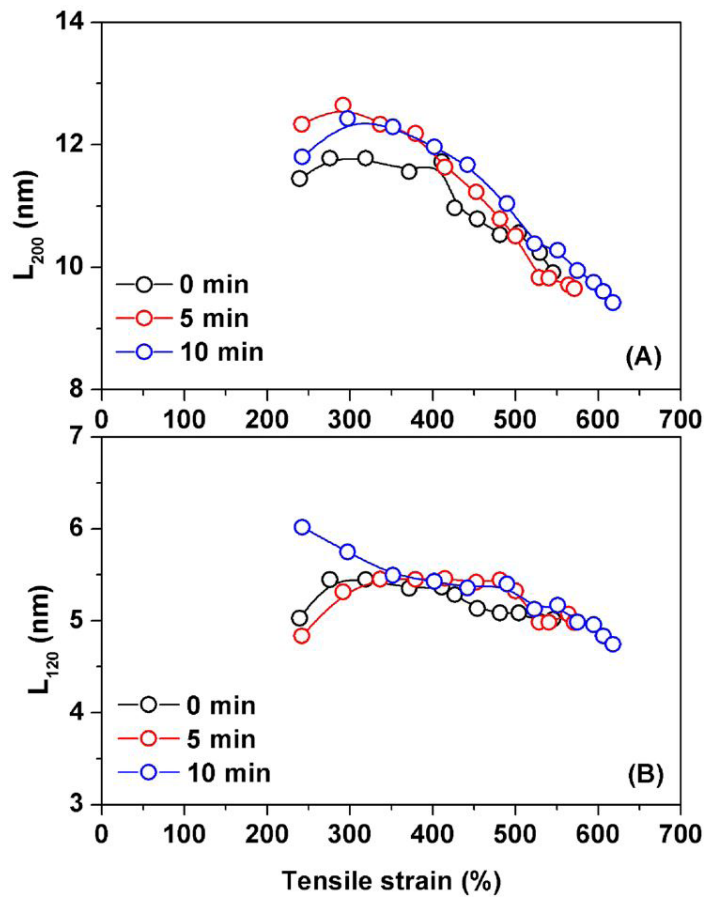

Figure 5. Variation of crystallite size at various strains in the NR vulcanizates prepared with different mastication times.

function (OP) was used to estimate the degree of crystallite orientation. The degree of crystallite orientation was calculated from the azimuthal intensity distribution of the (120) plane. The OP approaches 1 when the crystallites are completely aligned along the stretching direction, while 
the value is 0 for crystals that are randomly oriented, and 0.5 when the crystals are aligned perpendicular to the stretching direction ${ }^{[13]}$. Figure 6 shows the OP for NR vulcanizates prepared with different mastication times, as functions of strain. The OP slightly increased with strain and approached 1, implying that the alignment of crystallites was almost parallel to the stretching direction. The results obtained in recent studies align well with these observations ${ }^{[30,31]}$.

Since the SAXS intensity patterns of the vulcanized rubber samples were attributed to the presence of crosslinked networks ${ }^{[32,33]}$, the variations of crosslinked networks were investigated. Effects of the mastication time on dispersion and size of crosslinked network structures were investigated by using the SAXS measurement, and the results are shown in Figures 7 and 8.

Figure 7 shows a plot of the scattering intensity $\mathrm{I}(\mathrm{q})$ against scattering vector $\mathrm{q}$ for the NR vulcanizates prepared with different mastication times. The $\mathrm{q}$ is defined as: $\mathrm{q}=$ $(4 \pi \sin \theta) / \lambda ; \lambda$ is the wavelength and $2 \theta$ is the scattering angle. From Figure 7, a reduction of molecular weight with increasing mastication time slightly affected the SAXS profile of the vulcanizate. This was attributed to the fact that there was only reorientation of scattering bodies such as a crosslinked network ${ }^{[34]}$. The I(q) in all cases decreased continuously with increasing $\mathrm{q}$ and the $\mathrm{I}(\mathrm{q})$ was almost constant when the value of q approached 0.2 . However, the lowest intensity was observed for the sample with $5 \mathrm{~min}$ of mastication, suggesting a homogeneous distribution of the crosslinked networks throughout the rubber matrix ${ }^{[9]}$. The homogeneity of crosslinked networks clearly contributed to the tensile properties and thus the highest tensile strength was obtained for the sample with 5 min mastication. This clearly confirms the importance of crosslinked networks to tensile properties.

To gain further details of network structural differences in vulcanizate samples prepared with varied mastication times, the SAXS profiles were then fitted with the Guinier equation. Figure 8 shows typical Guinier plots (Ln I(q) versus $\mathrm{q}^{2}$ ) for the crosslinked NR samples. The data in Figure 8 were fitted with straight lines with $\mathrm{R}$-squared of 0.99. It can be seen that the slope decreased with mastication time. From the slopes obtained from Figure 8 , the $\mathrm{Rg}$ can be estimated, and the results are shown in Figure 9.

Figure 9 shows changes in size of crosslinked network structures in the NR vulcanizates prepared with different mastication times. The $\mathrm{R}_{\mathrm{g}}$ slightly decreased with mastication time, implying that the size of crosslinked networks in the vulcanizates was reduced with decreasing rubber molecular weight. A reduction of $\mathrm{R}_{\mathrm{s}}$ would be attributed to the decreased number of high molecular weight chains that participated in crosslinking. This study suggests not only the variation of crosslinked structures with decreasing molecular weight caused by mastication, but also suggests reduction in size of crosslinked structures with decreasing molecular weight. As compared to NR without vulcanization ${ }^{[9]}$, the size of $\mathrm{R}_{\mathrm{g}}$ for the vulcanized rubber was larger. This is due to the fact that the $R_{g}$ in unvulcanized NR was attributed to the aggregation of impurities (non-rubber components) ${ }^{[35]}$, but the $\mathrm{R}_{\mathrm{g}}$ in the vulcanized sample was due to crosslinking of clusters by all impurities, activating agents and crosslinking agents ${ }^{[36]}$. Therefore, a larger $\mathrm{R}_{\mathrm{g}}$ was achieved for samples after vulcanization.

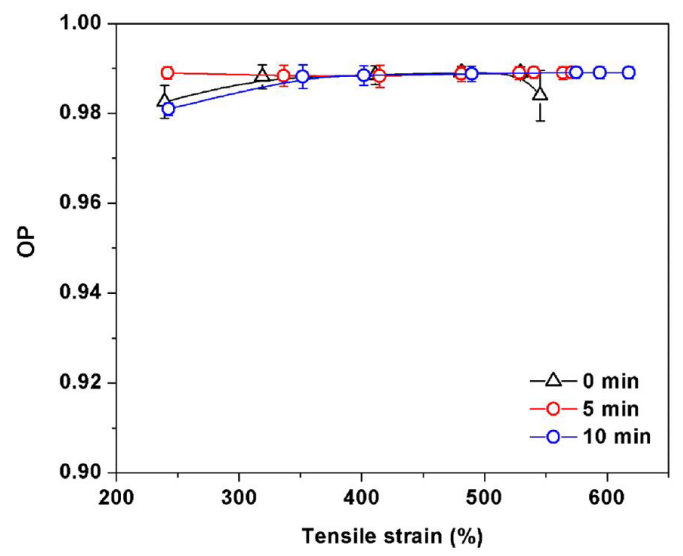

Figure 6. Orientation of crystallinity at various strains in the NR vulcanizates prepared with different mastication times.

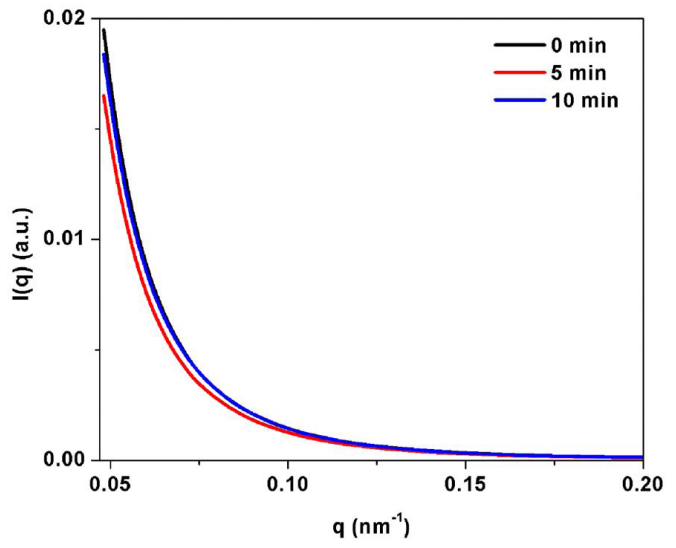

Figure 7. Correlation of scattering intensity $\mathrm{I}(\mathrm{q})$ with scattering vector $\mathrm{q}$ for $\mathrm{NR}$ vulcanizates prepared with different mastication times.

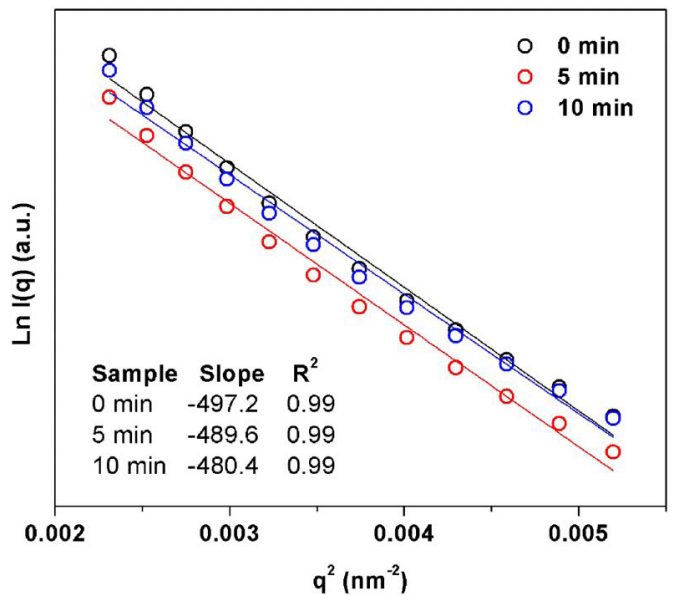

Figure 8. Typical Guinier plots for NR vulcanizates prepared with different mastication times. 


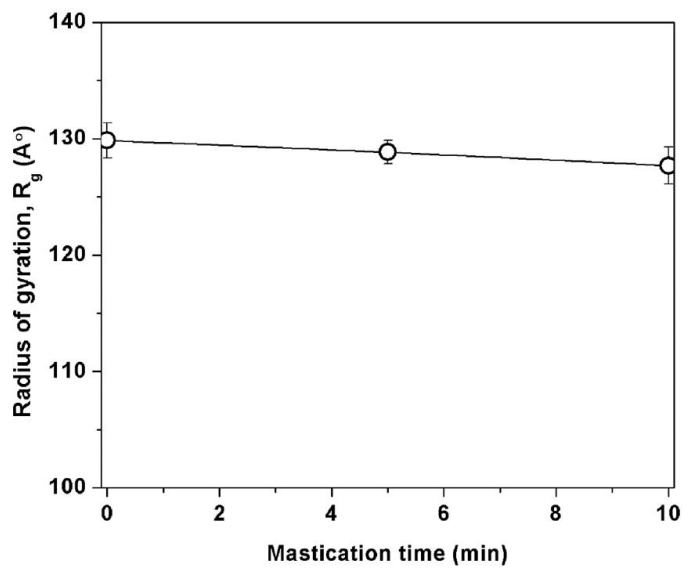

Figure 9. Radius of gyration $\left(\mathrm{R}_{\mathrm{g}}\right)$ for the NR vulcanizates prepared with different mastication times.

\section{Conclusions}

In this study, influences of mastication times on the tensile response, the deformation-induced crystallization and the molecular structure of NR vulcanizates were investigated. Increased mastication time slightly enhanced the crosslink density in rubber vulcanizates. The stress response to tensile deformation tended to decrease with increasing mastication time, which agrees well with the deformation-induced crystallization behavior. Increased mastication time significantly affected modulus at specified strain and upturn point of strain induced-crystallization of the crosslinked samples. Prolonged mastication decreased chain crystallization during stretching and size of crosslinked networks due to shorter rubber polymer chains. Based on the results obtained in this study, it is suggested that prolonged mastication influenced the deformation induced crystallization and structural homogeneity of the crosslinked NR, which in turn affected the tensile properties.

\section{Acknowledgements}

Financial support from the Prince of Songkla University (Grant No. RDO6202102S) to the first author is gratefully acknowledged. Research and Development Office (RDO), Prince of Songkla University and Assoc. Prof. Dr. Seppo Karrila are acknowledged for assistance in editing the English language in this manuscript. The SCG chemicals is acknowledged for in-house developed extensometer during WAXD and SAXS measurements.

\section{References}

1. Smitthipong, W., Suethao, S., Shah, D., \& Vollrath, F. (2016). Interesting green elastomeric composites: silk textile reinforced natural rubber. Polymer Testing, 55, 17-24. http://dx.doi. org/10.1016/j.polymertesting.2016.08.007.

2. Noordermeer, J. W. M. (1998). Recent developments in rubber processing leading to new applications such as the "Green Tire”. Macromolecular Symposia, 127(1), 131-139. http:// dx.doi.org/10.1002/masy.19981270118.

3. Fries, H., \& Pandit, R. R. (1982). Mastication of rubber. Rubber Chemistry and Technology, 55(2), 309-327. http:// dx.doi.org/10.5254/1.3535880.
4. Flory, P. J. (1946). Effects of molecular structure on physical properties of butyl rubber. Industrial \& Engineering Chemistry, 38(4), 417-436. http://dx.doi.org/10.1021/ie50436a023.

5. Kok, C. M. (1985). The effect of molecular weight on the physical properties of U.V. degraded natural rubber. European Polymer Journal, 21(1), 37-40. http://dx.doi.org/10.1016/00143057(85)90062-X.

6. Ono, K., Kato, A., \& Murakami, K. (1985). Unusual stressstrain properties of natural rubber vulcanizates with high primary molecular weight. Polymer Bulletin, 13(1), 29-33. http://dx.doi.org/10.1007/BF00264237.

7. Huneau, B. (2011). Strain-induced crystallization of natural rubber: A review of x-ray diffraction investigations. Rubber Chemistry and Technology, 84(3), 425-452. http://dx.doi. org/10.5254/1.3601131.

8. Ehabe, E. E., Bonfils, F., Sainte-Beuve, J., Collet, A., \& Schue, F. (2006). High-temperature mastication of raw natural rubber: changes in macrostructure and mesostructure. Polymer Engineering and Science, 46(2), 222-227. http://dx.doi. org/10.1002/pen.20433.

9. Hayeemasae, N., Waesateh, K., Soontaranon, S., \& Masa, A. (2020). The effect of mastication time on the physical properties and structure of natural rubber. Journal of Elastomers and Plastics. http://dx.doi.org/10.1177/0095244320928566.

10. Dick, J. S. (2003). Basic rubber testing: selection methods for a rubber testing program. Pennsylvania: ASTM International. http://dx.doi.org/10.1520/MNL39-EB.

11. Khang, T. H., \& Ariff, Z. M. (2012). Vulcanization kinetics study of natural rubber compounds having different formulation variables. Journal of Thermal Analysis and Calorimetry, 109(3), 1545-1553. http://dx.doi.org/10.1007/s10973-011-1937-3.

12. Flory, P. J., \& Rehner, J. Jr (1943). Statistical mechanics of crossLinked polymer networks II. swelling. The Journal of Chemical Physics, 11(11), 521-526. http://dx.doi.org/10.1063/1.1723792.

13. Tosaka, M., Murakami, S., Poompradub, S., Kohjiya, S., Ikeda, Y., Toki, S., Sics, T., \& Hsiao, B. S. (2004). Orientation and crystallization of natural rubber network as revealed by WAXD using synchrotron radiation. Macromolecules, 37(9), 3299-3309. http://dx.doi.org/10.1021/ma0355608.

14. Ikeda, Y., Yasuda, Y., Hijikata, K., Tosaka, M., \& Kohjiya, S. (2008). Comparative study on strain-induced crystallization behavior of peroxide cross-linked and sulfur cross-linked natural rubber. Macromolecules, 41(15), 5876-5884. http:// dx.doi.org/10.1021/ma800144u.

15. Somani, R. H., Yang, L., Zhu, L., \& Hsiao, B. S. (2005). Flow-induced shish-kebab precursor structures in entangled polymer melts. Polymer, 46(20), 8587-8623. http://dx.doi. org/10.1016/j.polymer.2005.06.034.

16. Roe, R. J. (2000). Methods of x-ray and neutron scattering in polymer science. New York: Oxford University Press.

17. Lee, C. H., Saito, H., Inoue, T., \& Nojima, S. (1996). Timeresolved small-angle $\mathrm{x}$-ray scattering studies on the crystallization of poly(ethylene terephthalate). Macromolecules, 29(22), 7034-7037. http://dx.doi.org/10.1021/ma951828m.

18. Masa, A., Saito, H., Sakai, T., Kaesaman, A., \& Lopattananon, N. (2017). Morphological evolution and mechanical property enhancement of natural rubber/polypropylene blend through compatibilization by nanoclay. Journal of Applied Polymer Science, 134(10), 44574. http://dx.doi.org/10.1002/app.44574.

19. Dimier, F., Vergnes, B., \& Vincent, M. (2004). Relationships between mastication conditions and rheological behavior of a natural rubber. Rheologica Acta, 43(2), 196-202. http://dx.doi. org/10.1007/s00397-003-0342-7.

20. Smitthipong, W., Tantatherdtam, R., Rungsanthien, K., Suwanruji, P., Klanarong, S., Radabutra, S., Thanawan, S., Vallat, M. F., Nardin, M., Mougin, K., \& Chollakup, R (2013). Effect of 
non-rubber components on properties of sulphur crosslinked natural rubbers. Advanced Materials Research, 844, 345-348. http://dx.doi.org/10.4028/www.scientific.net/AMR.844.345.

21. Kongkaew, C., Intiya, W., Loykulnant, S., \& Sae-oui, P. (2017). Effect of protein crosslinking by maillard reaction on natural rubber properties. KGK. Kautschuk, Gummi, Kunststoffe, 5, $37-41$.

22. Karaagac, B., Cengiz, S. C., Bayram, T., \& Sen, M. (2018). Identification of temperature scanning stress relaxation behaviors of new grade ethylene propylene diene elastomers. Advances in Polymer Technology, 37(8), 3027-3037. http:// dx.doi.org/10.1002/adv.21973.

23. Ray, S., \& Cooney, R. P. (2018). Thermal degradation of polymer and polymer composites. In M. Kutz (Ed.), Handbook of environmental degradation of materials (pp. 185-206). Oxford: William Andrew Publishing. http://dx.doi.org/10.1016/ B978-0-323-52472-8.00009-5.

24. Bueche, F. (1958). Mechanical properties of natural and synthetic rubbers. Rubber Chemistry and Technology, 31(1), 1-18. http://dx.doi.org/10.5254/1.3542259.

25. Tosaka, M. (2007). Strain-induced crystallization of crosslinked natural rubber as revealed by $\mathrm{x}$-ray diffraction using synchrotron radiation. Polymer Journal, 39(12), 1207-1220. http://dx.doi. org/10.1295/polymj.PJ2007059.

26. Tosaka, M., Senoo, K., Kohjiya, S., \& Ikeda, Y. (2007). Crystallization of stretched network chains in cross-linked natural rubber. Journal of Applied Physics, 101(8), 084909. http://dx.doi.org/10.1063/1.2716382.

27. Trabelsi, S., Albouy, P. A., \& Rault, J. (2003). Crystallization and melting processes in vulcanized stretched natural rubber. Macromolecules, 36(20), 7624-7639. http://dx.doi.org/10.1021/ $\mathrm{ma} 030224 \mathrm{c}$.

28. Chenal, M., Chazeau, L., Guy, L., Bomal, Y., \& Gauthier, C. (2007). Molecular weight between physical entanglements in natural rubber: A critical parameter during strain-induced crystallization. Polymer, 48(4), 1042-1046. http://dx.doi. org/10.1016/j.polymer.2006.12.031.

29. Klug, H. P., \& Alexander, L. E. (1974). X-ray diffraction procedures: For polycrystalline and amorphous materials. New York: Wiley.
30. Che, J., Burger, C., Toki, S., Rong, L., Hsiao, B. S., Amnuaypornsri, S., \& Sakdapipanich, J. (2013). Crystal and crystallites structure of natural rubber and synthetic cis-1,4-polyisoprene by a new two dimensional wide angle x-ray diffraction simulation method, I, strain-induced crystallization. Macromolecules, 46(11), 4520-4528. http://dx.doi.org/10.1021/ma400420k.

31. Che, J., Burger, C., Toki, S., Rong, L., Hsiao, B. S., Amnuaypornsri, S., \& Sakdapipanich, J. (2013). Crystal and crystallites structure of natural rubber and peroxide-vulcanized natural rubber by a two-dimensional wide-angle $\mathrm{x}$-ray diffraction simulation method, II, strain-induced crystallization versus temperatureInduced crystallization. Macromolecules, 46(24), 9712-9721. http://dx.doi.org/10.1021/ma401812s.

32. Salgueiro, W., Somoza, A., Torriani, I. L., \& Marzocca, A. J. (2007). Cure temperature influence on natural rubber - a small angle x-ray scattering study. Journal of Polymer Science. Part B, Polymer Physics, 45(21), 2966-2971. http://dx.doi. org/10.1002/polb.21293.

33. Masa, A., Soontaranon, S., \& Hayeemasae, N. (2020). Influence of sulfur/accelerator ratio on tensile properties and structural inhomogeneity of natural rubber. Polymer, 44(4), 519-526. http://dx.doi.org/10.7317/pk.2020.44.4.519.

34. Weng, G., Huang, G., Lei, H., Qu, L., Nie, Y., \& Wu, J. (2011). Crack initiation and evolution in vulcanized natural rubber under high temperature fatigue. Polymer Degradation \& Stability, 96(12), 2221-2228. http://dx.doi.org/10.1016/j. polymdegradstab.2011.09.004.

35. Karino, T., Ikeda, Y., Yasuda, Y., Kohjiya, S., \& Shibayama, M. (2007). Nonuniformity in natural rubber as revealed by small-angle neutron scattering, small-angle X-ray scattering, and atomic force microscopy. Biomacromolecules, 8(2), 693 699. http://dx.doi.org/10.1021/bm060983d. PMid:17243766.

36. Ikeda, Y., Higashitani, N., Hijikata, K., Kokubo, Y., Morita, Y., Shibayama, M., Osaka, N., Suzuki, T., Endo, H., \& Kohjiya, S. (2009). Vulcanization: new focus on a traditional technology by small-angle neutron scattering. Macromolecules, 42(7), 2741-2748. http://dx.doi.org/10.1021/ma802730z.

Received: Oct. 07, 2020

Revised: Jan. 25, 2021

Accepted: Feb. 15, 2021 